\title{
Guidance for full-thickness suturing in endoscopic sleeve gastroplasty - preliminary exploration using laparoscopy
}

Endoscopic sleeve gastroplasty (ESG) is a new endoscopic weight loss procedure that creates a sleeve along the gastric greater curvature using a full-thickness endoscopic suturing device [1-3]. However, there is no specific guide for fullthickness suturing in ESG.

The patient here described had a body weight of $116 \mathrm{~kg}$ and a body mass index (BMI) of $36.2 \mathrm{~kg} / \mathrm{m}^{2}$. The patient had a history of hypertension for more than 10 years. With the patient under a general anesthetic, argon plasma coagulation (APC) was used to mark the stitch sites along the anterior wall, greater curvature, and posterior wall of the stomach ( $\triangleright$ Fig.1a). We used a triangular stitch pattern, starting at the anterior wall, then the greater curvature, and finally the posterior wall, targeting the APC markings ( Fig.1b). Each triangular suture pattern consisted of approximately six full-thickness stitches, which were then cinched together to form a plication. A total of six plications were placed to reduce the gastric lumen significantly ( Fig. $1 \mathrm{c}$ ).

Throughout the procedure, laparoscopy was used to observe and help control the force applied with the helix of the suturing device, with the operators being advised when they were pushing too hard on the helix, so as to prevent damage within the abdominal cavity
( $\triangleright$ Fig. 1d). Otherwise, the laparoscope was used to observe directly whether the helix had penetrated the stomach. Additionally, we explored how many times the helix should be rotated and found that the mucosa shrank after four rotations of the helix ( $\triangleright$ Fig. 1 e,f). Suturing at the fundus and posterior wall was however difficult to observe laparoscopically, so in these areas we used the standard approach described previously to achieve full-thickness sutures.

The procedure took 70 minutes for the stitching and used six sutures $(\triangleright$ Video 1$)$. There were no adverse events. During the 3 -month follow-up period, the patient did not complain of
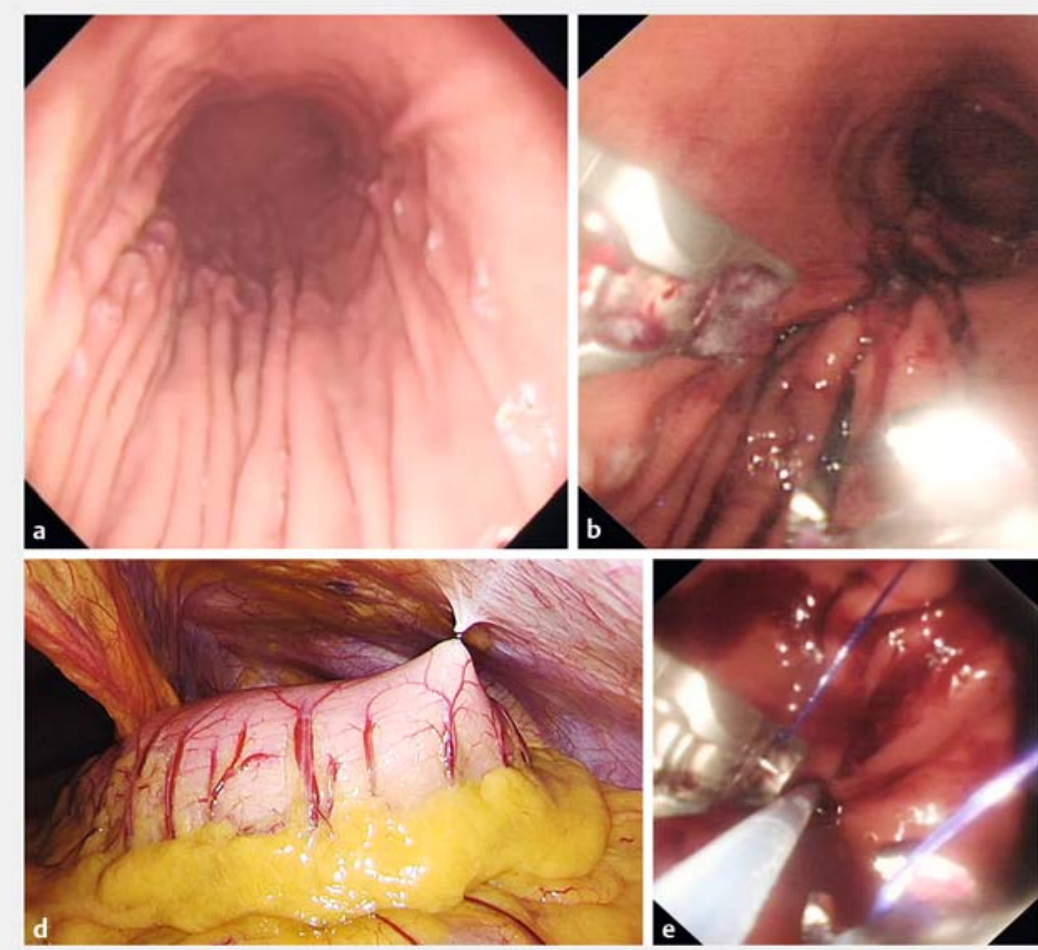
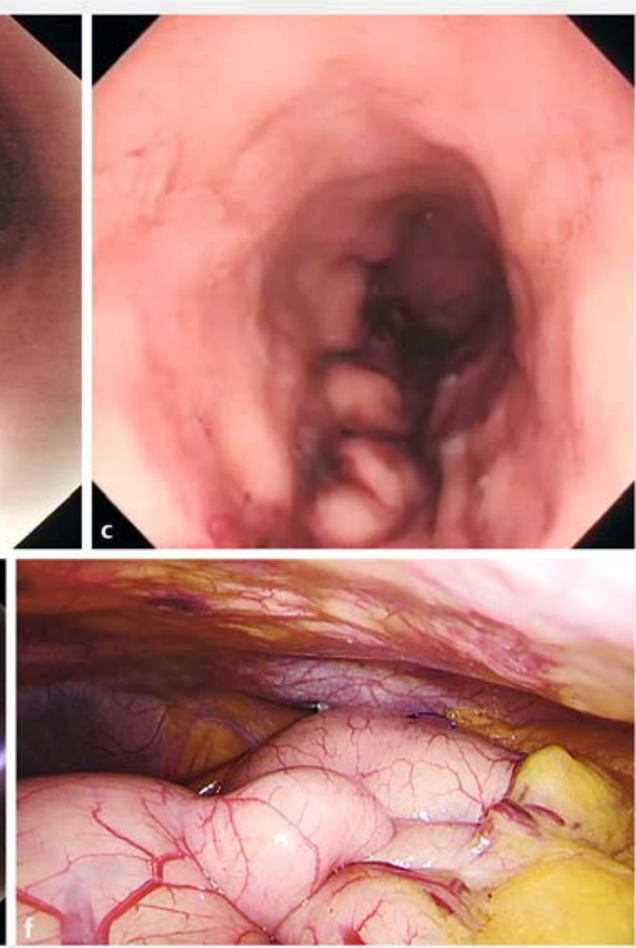

- Fig. 1 Endoscopic and laparoscopic images showing the endoscopic sleeve gastroplasty procedure. a First, marks were made using argon plasma coagulation (APC) along the anterior wall, greater curvature, and posterior wall of the stomach; $\mathbf{b}$ a triangular stitch pattern was then made guided by the APC marks, which resulted in; $\mathbf{c}$ a reduced gastric lumen. $\mathbf{d}$ The laparoscopic view allowed any damage to be identified in the abdominal cavity. $\mathbf{e}$ It was found that the mucosa shrank after four rotations of the helix, producing; $\mathbf{f}$ full-thickness sutures, seen here in laparoscopic view. 


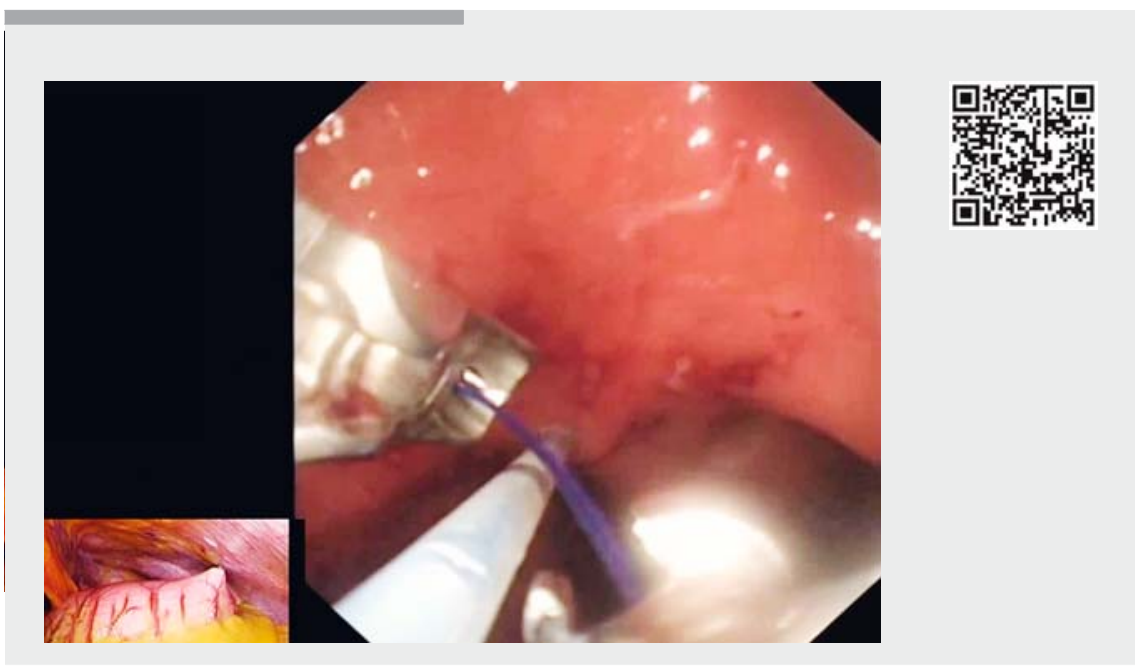

Video 1 Endoscopic and laparoscopic views showing how the endoscopic sleeve gastroplasty procedure can be guided laparoscopically.

\section{References}

[1] Caglar E, Dobrucali A, Bal K. Gastric balloon to treat obesity: filled with air or fluid? Dig Endosc 2013; 25: $502-507$

[2] Mansour S, Hou D, Rattan R et al. Non-alcoholic steatohepatitis mimicking liver metastasis in obesity surgery. Dig Endosc 2011; 23: $316-318$

[3] Lopez-Nava G, Sharaiha RZ, Vargas E] et al. Endoscopic sleeve gastroplasty for obesity: a multicenter study of 248 patients with 24 months follow-up. Obes Surg 2017; 27: 2649-2655

\section{Bibliography}

DOI https://doi.org/10.1055/a-0820-1294

Published online: 11.1.2019

Endoscopy 2019; 51: E61-E62

(c) Georg Thieme Verlag KG

Stuttgart · New York

ISSN 0013-726X

any further abdominal discomfort and lost $16 \mathrm{~kg}$ in weight.

In conclusion, ESG offers an important opportunity to deliver an effective weight loss intervention and the helix should rotate four turns until the mucosa shrinks to ensure a full-thickness suture.

Endoscopy_UCTN_Code_TTT_1AO_2AN

Competing interests

None

\section{The authors}

Lei Peng ${ }^{*}$, Xuan Li ${ }^{*}$, Guoxin Zhang

Department of Gastroenterology, First Affiliated Hospital of Nanjing Medical University, Nanjing, China

Corresponding author

\section{Guoxin Zhang, MD}

Department of Gastroenterology, First Affiliated Hospital of Nanjing Medical University, Nanjing, China

Fax: +86-025-83714511

guoxinz@njmu.edu.cn

* Contributed equally to this work

\section{ENDOSCOPY E-VIDEOS}

https:/|eref.thieme.de/e-videos

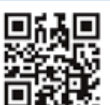

Endoscopy E-Videos is a free access online section, reporting on interesting cases and new

techniques in gastroenterological endoscopy. All papers include a high quality video and all contributions are freely accessible online.

This section has its own submission website at https://mc.manuscriptcentral.com/e-videos 